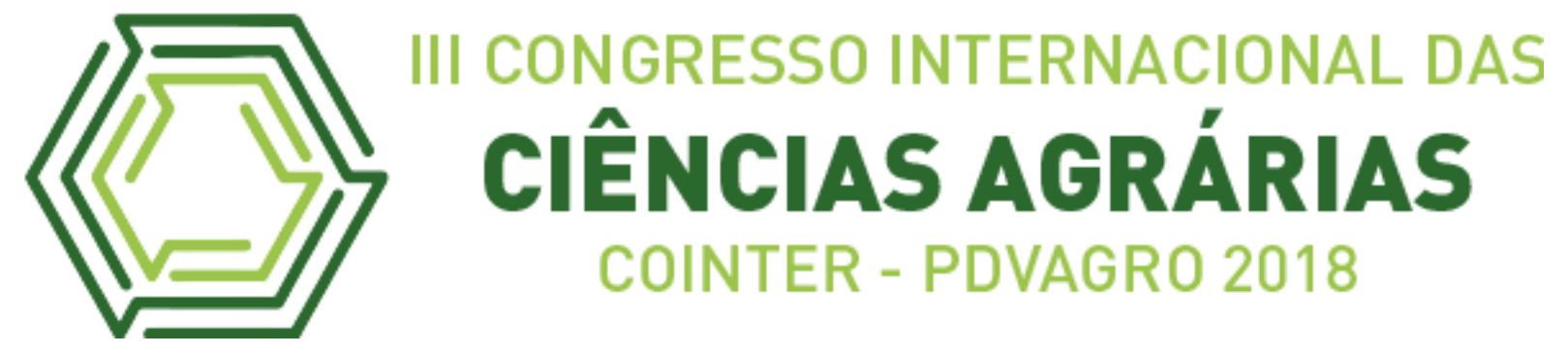

\title{
HORTA COMUNITÁRIA DE BASE AGROECOLÓGICA COMO FERRAMENTA PARA DESPERTAR VOCAÇÕES
}

\section{COMMUNITY AGRICULTURAL HORTA AS A TOOL FOR AWAKENING VOCATIONS}

\author{
Apresentação: Relato de Experiência \\ Taynara Mikely da Silva ${ }^{1}$; Adriano Silva de Vasconcelos ${ }^{2}$; Djalma Vitorino Costa Filho ${ }^{3}$
}

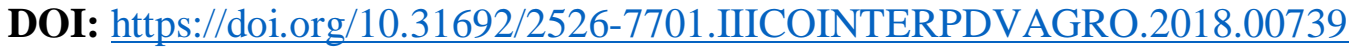

\section{Introdução}

As hortas comunitárias são espaços produtivos que agregam múltiplos saberes, convivência e integração entre a comunidade, além de recriar a paisagem, gerando novas funções sociais para o espaço. $\mathrm{O}$ acesso a um alimento saudável e de boa qualidade é um direito universal dos povos e deve sobrepor-se a qualquer fator econômico, político ou cultural que impeça sua efetivação. E, neste sentido, todas as pessoas devem ter direito a um abastecimento alimentar seguro, culturalmente apropriado, em quantidade e qualidade suficientes para garantir seu desenvolvimento integral (ARRUDA, 2006; BORGES et al., 2011).

Por meio da construção da horta comunitária agroecológica, contribuindo para a produção de alimentos saudáveis para população e, ao mesmo tempo, para a promoção da Educação ambiental e da Segurança Alimentar e Nutricional.

\section{Relato de Experiência}

Esta atividade foi desenvolvida por mim e mais estudantes do PDVagro (Programa Despertando Vocações Para Ciências Agrárias), junto à comunidade da zona Rural do Sítio Quatis, em Feira Nova, PE. É importante ressaltar que as cidades, com sua população crescente, necessitam de áreas cultiváveis cada vez maiores, impondo assim um

\footnotetext{
${ }^{1}$ Técnico em Agropecuária, IFPE Campus Vitória de Santo Antão, taynaramikely200245@gmail.com

2 Técnico em Agropecuária, IFPE Campus Vitória de Santo Antão, adrianovasconcelos07@gmail.com

${ }^{3}$ Tecnólogo em Alimentos, IFPE Campus Vitória de Santo Antão, djalma.vitorino@vitoria.ifpe.edu.br
} 
desmatamento progressivo e exacerbado das áreas de vegetação nativa do planeta. As hortas comunitárias surgem como uma alternativa cuja produção pode abastecer a comunidade local e assim suprir a dependência de uma área consumidora à outra produtora, abastecer a comunidade local e assim suprir a dependência de uma área consumidora à outra produtora.

\section{Metodologia}

A execução do projeto centrou-se, em 18 de maio de 2018, na construção de uma horta comunitária de base agroecológica no ambiente comunitário, contando para isso com a participação da comunidade sendo orientadas pelos estudantes do programa.

Chegando ao local de instalação foi marcado em piquetes o local do levantamento dos canteiros para que não ficasse fora do tamanho que foi trabalhado $(0.80 \mathrm{~m}$ de largura $\times 1.20 \mathrm{~m}$ de comprimento). No total foi feto 4 canteiros no qual foram levantados e adubados com esterco bovino deixando assim a horta $100 \%$ agroecológica. O primeiro canteiro foi introduzida a cultura do coentro, o plantio é feito em canteiros definitivos, com altura entre 30 e 50 centímetros. O segundo canteiro foi introduzido à cultura da alface, que no qual foi plantado com o espaçamento de 30 centímetros entre as plantas e entre linhas. Terceiro canteiro foi plantado cebolinha comum, na qual foi plantada com o espaçamento de $0.25 \mathrm{x}$ $0.15 \mathrm{~m}$ entre si. Quarto canteiro foi produzido à cultura da couve que foi feito um transplantio de um canteiro do IFPE Campus Vitória de Santo Antão que foi levado e plantado na comunidade com um espaçamento de 0.40 m entre linhas e 0.50 m entre plantas.

O sistema de irrigação foi totalmente manual onde contou com ajuda da comunidade para ser realizada de forma correta tecnicamente. Foi prestada uma assistência técnica para observar como estava se desenvolvendo as culturas onde foi observado que tudo estava dentro dos padrões técnicos.

Imagem 1: Construção da Horta Comunitária. Fonte: Própria.

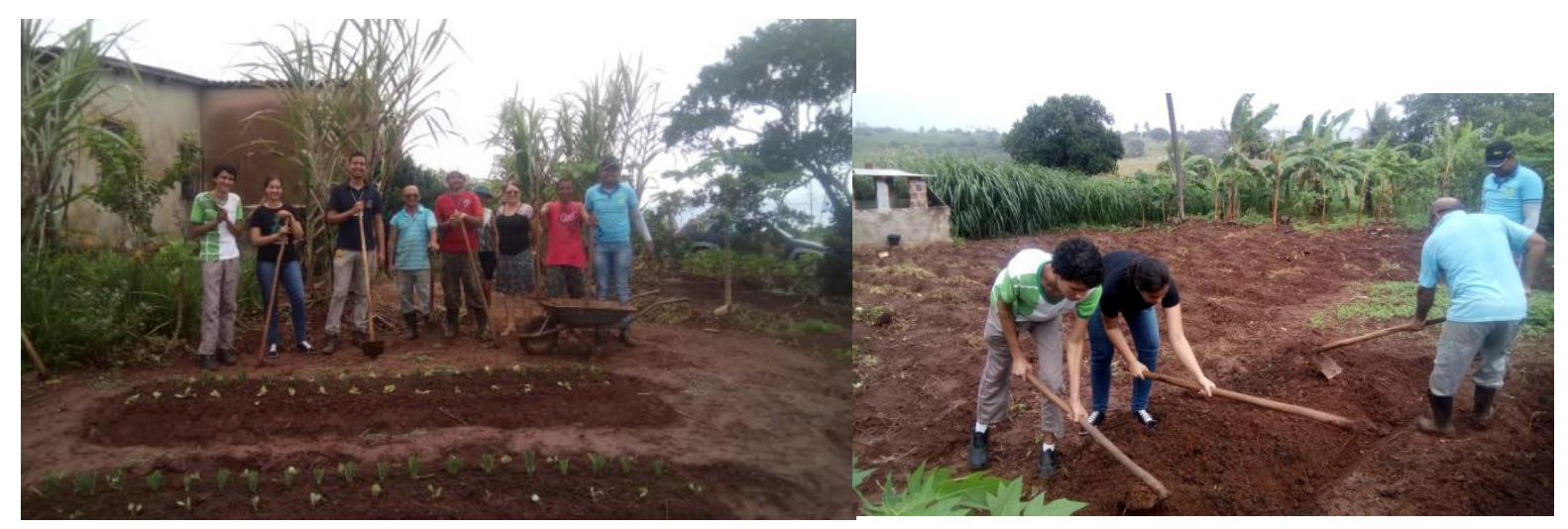




\section{Considerações}

Com o bom desenvolvimento e bons resultados que o projeto gerou na comunidade sempre quando podem se mobilizam para poder realizar mais atividades que no momento em vez de 4 canteiros que foi produzido da primeira vez, esse número aumentou para 6 canteiros só contando com a participação dos moradores da comunidade. As colheitas são planejadas e compartilhadas com os moradores da comunidade.

\section{Referências}

ARRUDA, J. Agricultura Urbana e Peri-urbana em Campinas/SP: análise do programa de hortas comunitárias como subsídio para políticas públicas. 2006. 147 p. Dissertação (Mestrado) - Engenharia Agrícola, Unicamp, Campinas, 2006.

BORGES, C.; MOREIRA, T.; TRAJBER, R. Espaços Educadores Sustentáveis. Rev. Salto para o Futuro. Brasília, vol. 21, n.07, junho, 2011. 